\title{
Strength of normal sections of double-ply rubcon- concrete flexural structures using as a binder of polybutadiene oligomers
}

\author{
Oleg Figovsky ${ }^{1, a}$, Yury Potapov ${ }^{2}$, Alexey Polikutin ${ }^{2, b}$ \\ ${ }^{1}$ International Nanotechnology Research Center "Polymate", Migdal Haemek, Israel \\ ${ }^{2}$ Voronezh State University of Architecture and Civil Engineering, \\ Voronezh, Russian Federation \\ a,bE-mail address: figovsky@gmail.com , a.pl@mail.ru
}

\begin{abstract}
This paper presents the research of the strength of normal sections of rubcon-concrete flexural members with different locations and ratios of the plies to reveal the effect of combing such materials in structures.
\end{abstract}

Keywords: strength; flexural members; double-ply structures; rubcon structures' rubcon-concrete structures

\section{INTRODUCTION}

Majority of cases of non-power destruction of reinforced concrete structures, specifically in conditions of aggressive media, is related to corrosion of reinforcement. In order to improve reliability and durability of reinforced concrete structures and at the same time to protect reinforcement against aggressive media, we suggest the use of rubcon in extended zone of flexural members, thus generating double-ply rubcon-concrete structures.

Rubcon (rubber concrete) is the state-of-the-art structural concrete with virtually universal corrosion resistance, based on rubber binder.

Large-tonnage technogeneous waste (for example, ash - production waste of thermal power plant) is used for its filling. While possessing the highest chemical stability, the rubcon is characterized by high compression and tensile strength, manufacturability etc.

Apart from this, favorable physical and mechanical properties of the rubcon located in the extended zone significantly contribute to crack resistance and reduction of deformability of the structures.

\section{EXPERIMENT, RESULTS AND DISCUSSION}

Manufacture and operation of supporting structures are not possible without the study of the work of such structures. It is particularly vital for the design of structures based on the 
modern materials. Rubcons refer to the materials of such kind. In this connection we pursued research of normal sections of flexural rubcon members.

To solve the tasks, we manufactured beams with dimensions of $60 \times 120 \times 1400 \mathrm{~mm}$ with various ply thickness and reinforcement percentage. Class A500C reinforcement was used as longitudinal reinforcement. Percentage of longitudinal reinforcement varied within 0.7 to $2.1 \%$, ply ratio $h_{\text {rubber }} / h_{\text {concrete }}$ changed from 0.33 to 1 . Double-ply structures were manufactured by separate concrete casting of plies. First, concrete plies were manufactured, and in 28 days rubcon plies were manufactured.

Concrete was matured at the temperature of $20 \pm 3{ }^{\circ} \mathrm{C}$ and humidity $70-90 \%$. Beam reinforcement and loading scheme is presented on Fig. 1. At such loading the zone of maximal bending moment is located in the middle of the beam (pure bending zone). In this section flexural moment remains constant.

Beams were tested on press P50. Loading was provided by two concentrated loads, continuously increasing up to destruction.
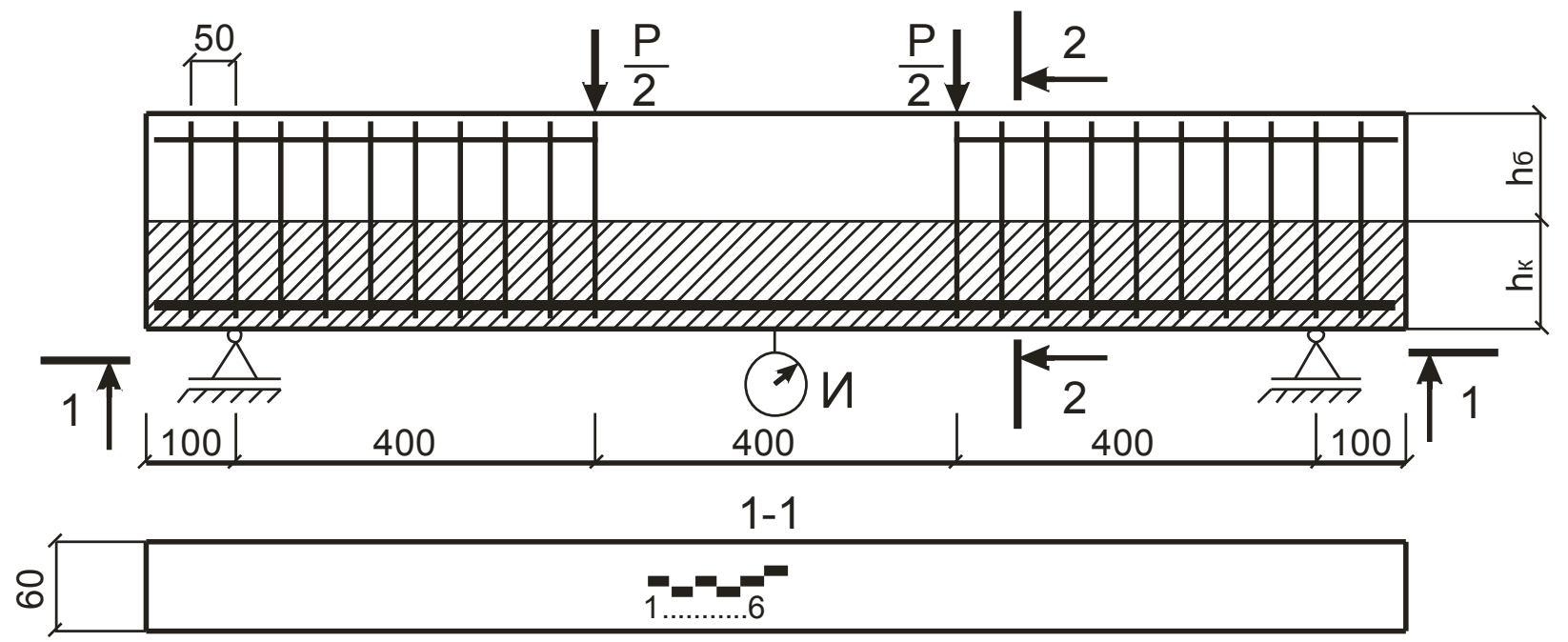

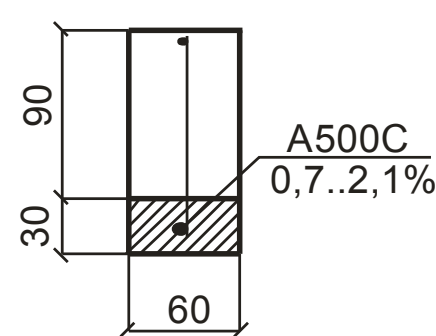

Series 1

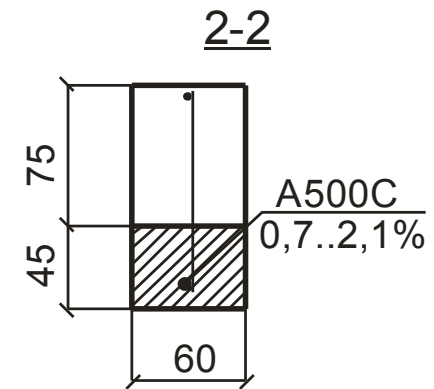

Series 2

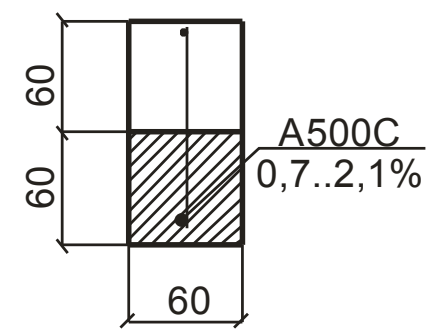

Series 3

Figure 1. Scheme of reinforcement, loading and installation of instruments during the test: $\mathrm{h}_{\bar{\sigma}}-$ thickness of concrete ply, $\mathrm{h}_{\text {rubcon }}-$ rubcon ply thickness 


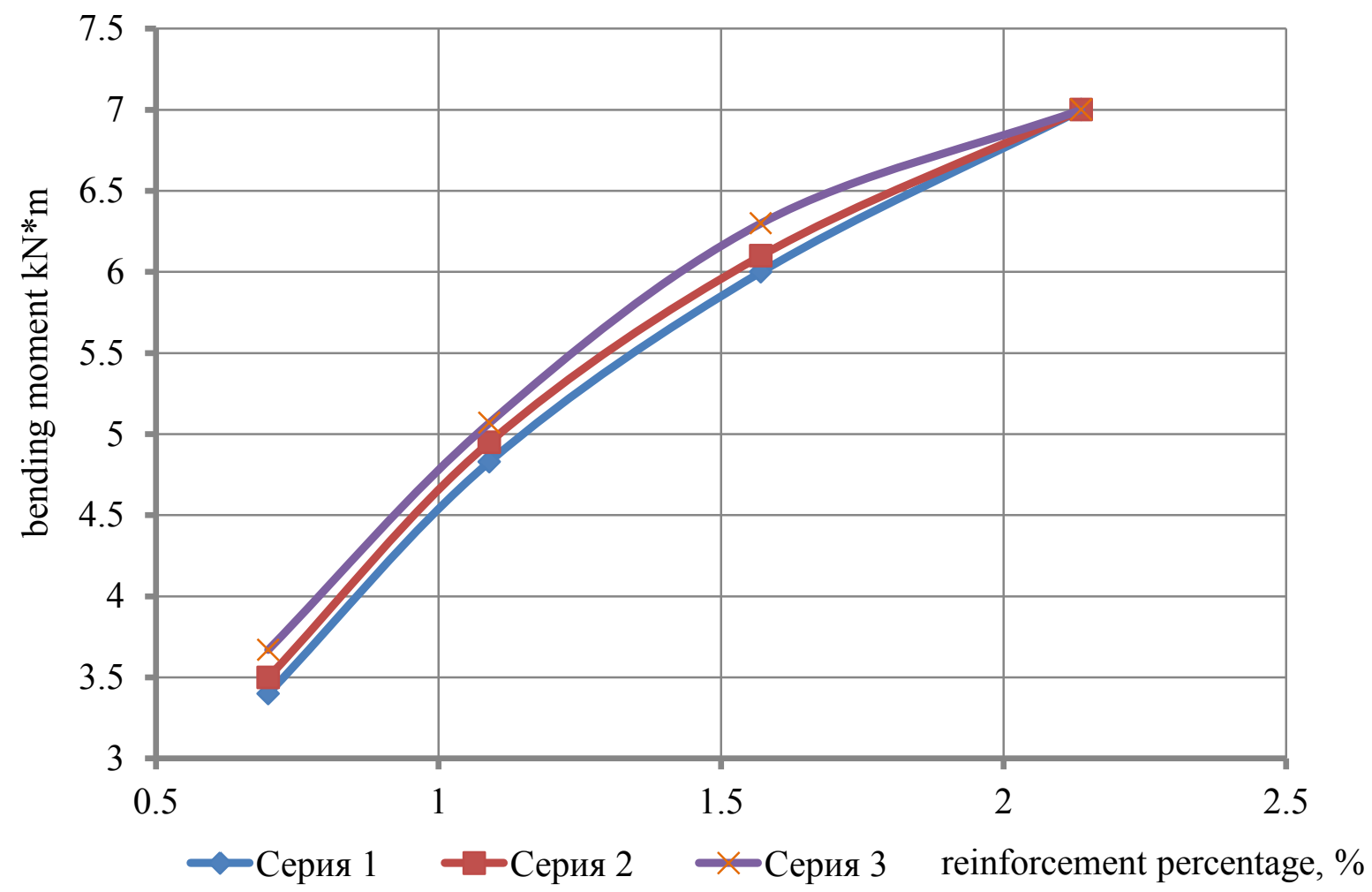

Figure 2. Dependence of carrying capacity of double-ply rubcon flexural members on percentage of longitudinal reinforcement.

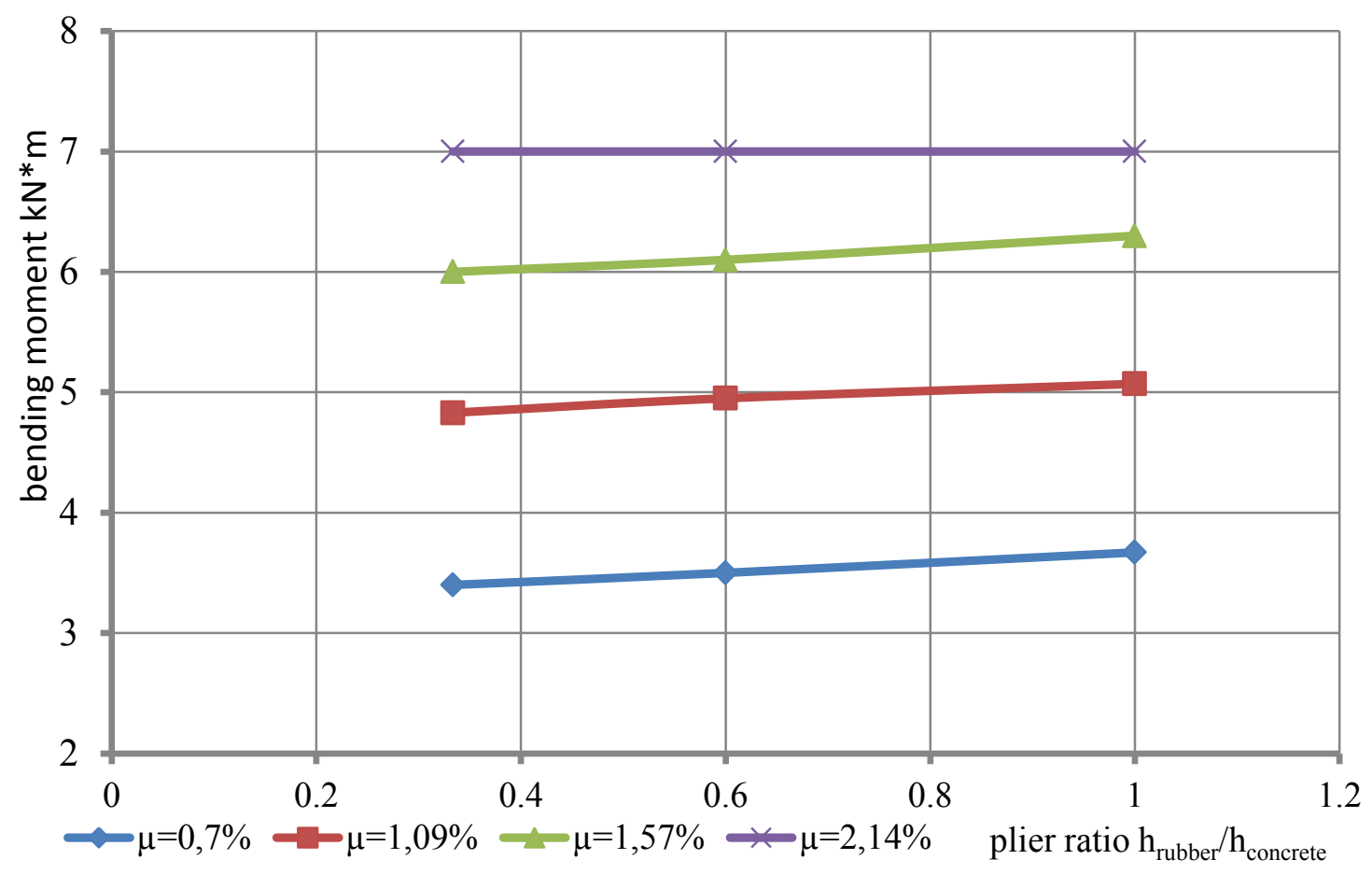

Figure 3. Dependence of carrying capacity of double-ply rubcon flexural members. on ply thickness ratio. 
Test results are presented as graphic functions of carrying capacity of section of normal double-ply rubcon flexural members on reinforcement percentage (Fig. 2) and on plies ratio $\mathrm{h}_{\text {rudcon }} / \mathrm{h}_{\text {concrete }}$ (Fig. 3).

\section{CONCLUSIONS}

Analysis of graphic functions of carrying capacity of normal sections of double-ply rubcon flexural members of the structures depending on percentage of longitudinal reinforcement and ply ratio $\left(\mathrm{h}_{\text {rubcon }} / \mathrm{h}_{\text {concrete }}\right)$ revealed that:

- in case of increase of longitudinal reinforcement percentage the strength of normal sections increases at any ratio of rubcon and concrete thickness. At percentage of longitudinal reinforcement $2,1 \%$ the structures break down completely in the compressed zone;

- in case of increase of longitudinal reinforcement percentage the strength of normal sections increases by curvilinear (exponential) relation;

- in case of increase of ply ratio $h_{\text {rubcon }} / h_{\text {concrete }}$ (at fixed value of longitudinal reinforcement percentage) the strength of normal sections also increases, however, to a lesser extent. In this case hardening of normal sections can be explained in the following way: given the increase of ply ratio, the bigger amount of rubcon is located in the extended zone, which has an effect on the strength of normal sections of flexural members, while the concrete of the extended area has virtually no effect on the strength of normal sections;

- increase of ply ratio $h_{\text {rubcon }} / h_{\text {concrete }}$ hardens the normal sections by linear dependence. At longitudinal reinforcement of $2.14 \%$ the strength of normal sections is virtually independent of thickness ratio of concrete and rubcon plies;

- the beams with rubcon and concrete ply ratio equal to 1 have the highest strength of normal sections.

\section{References}

[1] Figovsky Oleg, Beilin Dmitry. Advanced Polymer Concretes and Compounds. CRC Press, New York, 2014, pp. 245.

[2] Yu.B. Potapov., Yu.M. Borisow, S.A. Goshev. X-Ray Fluorescence Spectroscopy Analysis of Pyrolyzate of a Polymer Concrete Based on Polybutadiene Binder. Journal "Scientific Israel - Technological Advantages". "Scientific Herald" of Voronezh State University of Architecture and Civil Engineering, Vol.15, № 4, 2013. p. 11-17.

[3] Yu.M. Borisow, D.V. Panfilov, S.V. Kashtanov, Ye.M. Yudin. Stress - Strain Characteristics of Fiber Polymer Concrete Based on Polybutadiene Binder. Journal "Scientific Israel - Technological Advantages". "Scientific Herald" of Voronezh State University of Architecture and Civil Engineering, Vol.15, № 4, 2013. p. 30-37. 
[4] Yu.M. Borisow, A.E. Polikutin, A.C. Chudinov, M.M. Okunev, A.S. Bystrov. Study of T-flanges rubber concrete bended beams. Journal "Scientific Israel - Technological Advantages". "Scientific Herald" of Voronezh State University of Architecture and Civil Engineering, Vol.15, № 4, 2013. p. 65-72.

[5] Yu.M. Borisow, A.E. Polikutin, Nguen Fan Zuy. Study of Fiber Reinforced Rubber Concrete Structural Elements in Bending. Journal "Scientific Israel - Technological Advantages". "Scientific Herald" of Voronezh State University of Architecture and Civil Engineering, Vol.15, № 4, 2013. p. 45-64. 